\title{
Eigennamen im Bestand ungarischer Phraseologismen
}

0. In der Fachliteratur gab es schon seit mehreren Jahrzehnten diverse Bestrebungen, die Natur des Eigennamens (EN) in seiner Eigenschaft als Element der Lexik zu erhellen ${ }^{1}$, wobei man erst in der letzten Zeit von einem verhältnismäßigen Konsens sprechen kann.

Aufgrund der Ergebnisse der neueren Forschung läßt sich bei der inneren Charakterisierung der EN eine erkennbare Hierarchie der Seme beobachten. 2 Sie enthalten ein Archisem (Hauptsem): 'Einzelheit', differentielle Seme (obligatorische Seme): 'Belebtheit', 'Person', 'Konkretheit', 'Geschlecht' - bei Anthroponymen, und 'Unbelebtheit', 'Konkretheit', 'Lokalität' - bei Toponymen, sowie potentielle (fakultative) Seme. Die Ermittlung dieser Semtypen in der semantischen Struktur der EN demonstriert die semantischen Besonderheiten dieser sprachlichen Zeichen, so daß dadurch eine objektive Basis für die Untersuchung der Charakterzüge der EN als phraseologische Strukturkomponenten geschaffen wird.

Im vorliegenden Aufsatz interessieren uns vor allem neben den etymologisch-genetischen Aspekten der onymischen Phraseologismen der ungarischen Sprache die semantischen Prozesse und Leistungen bei der Idiomatisierung der EN. Es ist nämlich ein recht aufschlußreicher Fragenkomplex, ob der EN als selbständige lexikalische Einheit im Bestand von Phraseologismen desemantisiert wird oder seine onomastischen Merkmale beibehält und keiner vollständigen Fusion unterliegt.

1. Dank der Resultate der kontrastiven Sprachvergleiche ist schon bekannt, daß die Verwendung von EN als phraseologische Strukturelemente in den verschiedenen Sprachen unterschiedlich ausgeprägt ist. So soll dieses phraseologische Mikrosystem zum Beispiel im Bulgarischen bedeutend gewichtiger vertreten sein als im Russischen. ${ }^{3}$ W. Fleischer meint, daß dieser Strukturtyp im Deutschen nicht besonders stark frequentiert ist ${ }^{4}$, während eine frühere Untersuchung von uns ergab, daß - bezüglich ihrer Anzahl und Ver- 
breitung - den Phraseologismen mit Personennamen (PN) im Deutschen eine größere Rolle zukommt als im Ungarischen. ${ }^{5}$

Aber auch die ungarische Sprache der Gegenwart ist nicht arm an onymischen Phraseologismen: Allein das phraseographische Werk von G. O. Nagy $^{6}$ (im weiteren: ONG) führt mehr als 1500 onymische Wendungen auf. ${ }^{7}$

2. Im Zusammenhang mit dem Studium der onomastischen Phraseologismen tauchen die ersten Probleme bereits bei der Identifizierung des Untersuchungsgegenstandes auf.

2.1. Bei der eingehenden etymologisch-historischen Betrachtung der Phraseologismen stellt sich zuweilen heraus, daß der in ihnen enthaltene EN nur aus synchronem Blickwinkel gesehen als solcher gilt und in Wirklichkeit von einem Appellativum herzuleiten ist. Die ungarische Redensart $\delta / v k i$ se jobb a Deákné vásznánál [ONG 139] (= 'jd. ist nicht besser als der Durchschnitt; er hat auch seine Fehler') läßt die weibliche Form des verbreiteten Nachnamens 'Deák' vermuten, doch liegt hier wohl die ehemalige volkstümliche Bezeichnung des Dorflehrers (= 'deák'), d. h. ein Gattungsname, vor. ${ }^{8}$

2.2. Bisweilen wirft sogar die Abgrenzung der betreffenden Eigennamenklasse nicht geringe Schwierigkeiten auf. Hinter dem angenommenen Toponym kann nämlich ein PN (oder umgekehrt) stecken, der hochgradige formelle Ähnlichkeit (oder Indentität) mit einem tatsächlichen geographischen Namen aufweist. Die erste onymische Konstituente des ungarischen sprichwörtlichen Vergleichs messze van, mint Makó Jeruzsálemtốl [ONG 461] (= 'jd./etw. ist sehr weit') soll sich z. B. nach der Erklärung von B. Tóth ${ }^{9}$ nicht - wie zunächst einmal denkbar - auf die südungarische Stadt 'Makó' beziehen, sondern auf einen betrunkenen Soldaten des Königs Endre II., der sich während des Kreuzzuges 1217 schon im dalmatischen Spalato einbildete, in Jerusalem zu sein. Dementsprechend haben wir es hier nicht mit einem Toponym, sondern mit einem Familiennamen zu tun.

2.3. In vielen Fällen bezieht sich der angenommene EN nicht auf eine Person, sondern auf ein unbelebtes Denotat oder eine Erscheinung. Die Redensart (lassan/sokáig készül, mint a) Luca széke [ONG 446] (= 'etw. entsteht sehr langsam') kann auf einen Hexenaberglauben zurückgeführt werden und es wird darunter ein Stuhl verstanden, mit dessen Anfertigung traditionsgemäß um Mitternacht vor dem Luca-Tag (13. Dez.) begonnen wird. Hier 
meint man mit dem weiblichen Vornamen 'Luca' keine Person, sondern einen Namenstag. 10

2.4. Ferner wären auch manche adjektivischen Derivate von EN zu erwähnen - die allerdings selbst nicht mehr als EN zu bezeichnen sind -, bei denen nicht auf Anhieb klar ist, daß sich hinter ihnen EN verbergen. Im Falle solcher Redensarten wie gordiuszi csomó [MÉSZ II/1041] ${ }^{11}$ (= 'gordischer Knoten, d. h. eine unlösbar scheinende Aufgabe') oder bábeli nyelvzavar/zû̃ravar [MÉSZ 1/382] (= 'babylonische Sprachverwirrung') scheint zwar noch der Name des altphrygischen Königs Gordius I. bzw. die biblische Stadt Babylon (nach Gen. 11,9) durch, aber bei vielen ist der Bezug zum ursprünglichen Denotat schon derart verblaßt, daß ihn ein durchschnittlich gebildeter Sprachträger nicht mehr ohne weiteres herzustellen vermag. Z. B. lakónikus rövidség/válasz [MÉSz IV/563] (= 'lakonische Kürze/Antwort, d. h. wortkarg, einsilbig [aber treffend]'), nach der griechischen Landschaft 'Lakonien' im südöstlichen Teil des Peloponnes mit der Hauptstadt Sparta ${ }^{12}$ oder joviális kedély [MÉSZ III/679] (= 'joviales Benehmen, d. h. leutselig, wohlwollend, gönnerhaft') geht auf den Glauben zurück, der den nach dem römischen Göttervater benannten Planeten Jupiter als Ursache für menschliche Fröhlichkeit und Heiterkeit ansah und dadurch den Heiteren mit ioviālis ("der im Sternbild des Planeten Jupiter Geborene") bezeichnete. ${ }^{13}$

3. Nach der obigen Skizzierung der Grenzen des Untersuchungsobjekts und der damit verbundenen Schwierigkeiten wollen wir uns nun der konkreten Ergründung der Genese der onymischen Phraseologismen des Ungarischen zuwenden.

Wenn man etwas tiefer in das Phänomen der Redensarten mit EN eindringt, so fallen einem - dem Ursprung nach - zwei verschiedene Hauptgruppen auf.

(a) Die Phraseologismen, in deren Bestand der EN auf ein bestimmtes (reales oder erfundenes) Bezeichnetes zurückgeht, fassen wir als determinierte Einheiten zusammen ${ }^{14}$, vgl. megugrotta a Kinizsi Pál táncát [ONG 366] (= 'jd. wurde gründlich verhauen'), nach Pál Kinizsi (? - 1494) dem legendären Heerführer des Königs Matthias Corvinus; im Ausdruck vénebb a Mátránál [ONG 469] beispielsweise (= 'sehr alt') wird auf das nordungarische Mátra-Gebirge Bezug genommen. 
(b) Die phraseologischen Wendungen, die etymologisch von keinem konkreten Denotat herrühren, bezeichnen wir als indeterminier ${ }^{15}$, vgl. Olcsó János [ONG 314] (= 'Handwerker/Händler, der alles billig anfertigt/verkauft') oder Antal a fejed [ONG 45] (= 'du bist einfältig, dumm').

Diese Aufteilung läßt sich aber nicht immer problemlos vollziehen, zumal die Herkunft vieler Phraseologismen mit EN nicht mehr nachzuweisen ist. Um ihre Entstehungsgeschichte genau zurückverfolgen zu können, muß man die Forschungsergebnisse der Linguistik, Kulturgeschichte, Ethnographie, Folkloristik und anderer Disziplinen komplex berücksichtigen.

In bezug auf das Deutsche, Englische, Französische und Russische vertreten L. B. Garifulin und M. K. Antonova die Meinung, daß die Etymologie der überwiegenden Mehrheit der anthroponymischen Phraseologismen (etwa $95 \%)$ nachvollziehbar ist. ${ }^{16}$ Dementgegen betonen wir, daß es in jeder Sprache recht viele onymische Phraseologismen gibt, deren Herkunft nicht eindeutig herausgefunden werden kann (man denke z. B. an die ansehnliche Menge der sog. indeterminierten Ausdrücke). Durch die Unklarheit der Genese vieler Redensarten ist es heute synchronisch gesehen an sich nicht immer einleuchtend, ob man es mit einer determinierten oder indeterminierten Wendung zu tun hat. Beim sprichwörtlichen Vergleich $\varepsilon l$, mint Marci Hevesen [ONG 466] (= 'jd. hat es leicht, lebt fröhlich, ohne Sorgen') ist z. B. noch nicht ermittelt worden, ob in diesem Marci der Name einer bestimmten Persönlichkeit weiterlebt und wer das gegebenenfalls gewesen ist. 17

Für den Ursprung einiger onymischer Wendungen bietet die Fachliteratur mitunter sogar mehrere - ziehmlich heterogene - Deutungsversuche an, z. B. Samu nadrágja [ONG 589] (= 'etw. Unsicheres, Schlechtes'). 18

3.1. Im Hinblick auf die Herkunft der onymischen phraseologischen Strukturelemente sind im Ungarischen folgende Gruppen zu unterscheiden. ${ }^{19}$

3.1.1. Phraseologische Wendungen, in denen ungarische nationale EN vorkommen, z. B. Mátyás (király) lustája [ONG 470] (= 'sehr fauler Mensch'), mit dem Namen des ungarischen Königs Matthias I. (1443 - 1490) oder Tiszába hord vizet [ONG 673] (= 'Wasser in den Rhein/die Elbe tragen, d. h. etw. Uberflüssiges tun') - mit der Bezeichnung des ungarischen Flusses Theiß.

3.1.2. Phraseologische Einheiten, die nicht-ungarische (fremdsprachige) EN enthalten: z. B. Molotov-koktél ${ }^{20}$ (= 'Molotov-Cocktail, d. h. Brandflasche zur Panzerbekämpfung') oder a ködös Albion' ${ }^{21}$ (= 'England'). 
3. 1.3. Redensarten, in denen aus der Mythologie, der antiken Sagenwelt stammende EN reflektiert werden, z. B. Thália szentélye 22 (= 'Theater') oder Ariadne fonala ${ }^{23}$ (= 'Ariadnefaden').

3. 1.4. Phraseologismen, die biblische EN beinhalten, z. B. (olyan) vén, mint Matuzsálem [ONG 469] (= 'alt wie Methusalem, d. h. sehr alt'), nach dem biblischen Urvater, Großvater Noahs, der 969 Jahre alt geworden sein soll oder hitetlen Tamás[MÉSZ III/277] (= 'ein ungläubiger Thomas, d. h. jd., der an allem zweifelt, etw. nicht glauben will), nach dem Jünger Thomas, der nicht eher an die Auferstehung Jesu glauben wollte, als bis er dessen Wunden betastet hatte (Joh. 20, 24 - 29).

3.1.5. Idiomatische Wendungen, die wir bekannten Werken der Weltliteratur verdanken: z. B. Csipkerózsikaálmát alussza ${ }^{24}$ (= 'den Dornröschenschlaf schlafen, d. h. lange unbeweglich schlafen'), nach der Hauptfigur des gleichnamigen Märchens der Brüder Grimm, aus ihrem Buch "Kinder- und Hausmärchen" 1812 - 1814, oder mi néki Hecuba ${ }^{25}(=$ 'Was ist ihm Hekuba, d. h. ihm ist alles absolut egal'), nach W. Shakespeares klassischem Drama "Hamlet" II, 2.

3.1.6. Redensarten, die in geschichtlichen Ereignissen, weltweit bekannten Anekdoten usw. ihren Ursprung haben, z. B. kész Waterloo 26 (= 'völliger Zusammenbruch') unter Anspielung auf den Ort der entscheidenden Niederlage Napoleons I. gegen Wellington und Blücher.

3.1.7. Phraseologische Einheiten, die aus anderen Sprachen übernommen worden sind. Hierbei wären zwei Typen zu unterscheiden:

- direkte Entlehnungen

- phraseologische Lehnübersetzungen.

Schon aus dem Wesen der Phraseologie geht hervor, daß direkte Entlehnung nicht sehr häufig auftreten, was für die onomastischen Wendungen durch die spezifischen Besonderheiten des EN bedingt - noch weitaus stärker gilt. Wir konnten nur wenige Belege ermitteln, z. B. Don Juan ${ }^{27}$ (aus dem Spanischen) - nach Torso de Molinas Stück "El burlador de Sevilla..." (= Der Verführer von Sevilla) und W. A. Mozarts gleichnamiger Oper - als Bezeichnung für einen von unstillbarem Liebesverlangen getriebenen charmanten (aber unmoralischen) Frauenverführer.

Zu phraseologischen Lehnübersetzungen kommt es häufiger, z. B. Buridán szamara ${ }^{28}$ (= 'Buridans Esel, d. h. ein Mensch, dem die Wahl zwischen 
zwei gleichwertigen Gegenständen schwer wird'): aus dem Französischen, nach Jean Buridan (bei 1295 - 1366), dem bekannten scholastischen Philosophen.

Merkwürdig erscheint, daß die zwischensprachliche Kommunikation manchmal auch seltsame Phänomene hervorrufen kann. So können hie und da sogar fremdsprachige Gattungsnamen zur Herausbildung ungarischer onomastischer Phraseologismen führen. Der onymische Kern der Redensart tudja a Herkó páter [ONG 282] (interlinear übersetzt: 'das weiß der Pater Herkó', d. h. 'weiß der Himmel') geht - wohl durch Volksetymologie - vermutlich auf deutsch 'Herr Gott Vater' zurück, d. h. leitet sich von Appellativa her. ${ }^{29}$

Es gibt aber auch Fälle, wo der originale onymische Charakter des fremdsprachigen Phraseologismus im Ungarischen völlig verlorengeht, nicht mehr zu erkennen ist. Aus der bayr.-österr. Wendung er ist ein Doktor Simandl/Siemann ${ }^{30}$ (= 'er steht unter dem Regiment seiner Frau, er muß tun, was sie befiehlt') wurde im Ungarischen schlechthin szimándli ember. ${ }^{31}$

In diesem Zusammenhang ist der Entwicklungsprozeß eines scherzhaften ungarischen onymischen Ausdrucks, einer Neuprägung des 19. Jahrhunderts, ebenfalls äußerst aufschußreich: er läßt sich über das Deutsche bis zur Bibel zurückverfolgen. Rudolf Ágai, ein junger Journalist der Zeitung "Magyar Sajtó", hat te im Jahre 1863 einen Bericht über eine damalige Weltsensation, die erste Fahrt des Luftschiffes "Géant" zu schreiben. Statt am tatsächlichen Schauplatz in Paris mußte er aber in der ungarischen Hauptstadt arbeiten, so daß er sich nur auf die deutschsprachige Presse stützen konnte, wo es hieß: "Empor, empor, wir wollen so hoch hinauffliegen, wie Jakobs Leiter". Er hat den Satz Wort für Wort übersetzt und so erschien in der Nummer vom 13. Oktober das Musterbeispiel des falschen, sogar lächerlichen Ubersetzungsfehlers, indem er die biblische Wendung (nach Jakob 28, 11 13) nicht erkannte und sie als einen Personennamen auffaßte. So konstituierte er - aufgrund der damaligen Traditionen - aus dem vermuteten deutschen Namen eine ungarische Entsprechung (mit ungarischer Wortfolge): 'Leiter Jakab'. Seitdem gilt dieser Ausdruck als Sinnbild sämtlicher grober und z. T. komischer Ubersetzungsfehler. 32

3.2. Entsprechend dem Thema und dem Charakter unserer Ausführungen gebührt den Phraseologismen der ersten Gruppe das Hauptaugenmerk. Diese Konstruktionen sind sowohl unter genetisch-etymologischem Gesichtspunkt 
als auch hinsichtlich ihrer Struktur recht heterogen. Bezüglich der Herkunft des ungarischen ENs lassen sich hier folgende Typen beobachten ${ }^{33}$ :

3.2.1. Phraseologische Wendungen, die mit Ereignissen und Fakten sowie prominenten Persönlichkeiten der ungarischen Geschichte im Zusammenhang stehende EN enthalten, z. B. hosszúlsokáig tart, mint a Rákóczi lakodalma [ONG 573] (= 'etw. dauert äußerst lange'), mit Verweis auf den Fürsten von Siebenbürgen und Ungarn, den Freiheitskämpfer Ferenc Rákóczi II. (1676 1735).

3.2. 2. Redensarten, deren onymische Konstituente mit der ungarischen Literatur in Verbindung steht. Der idiomatisierte PN im volkstümlichen Ausdruck erôs, mint Toldi Miklós (unokája) [ONG 676] (= 'jd. ist sehr stark') gelangte durch die Vermittlung des "Toldi" von János Arany in die Allgemeinsprache.

3.2.3. Idiomatische Wendungen, in denen der EN auf volkstümliche Sagen, Legenden, Abzählreime, Lieder, Spiele oder Märchen zurückzuführen ist. Die Konstruktion vkiê/övé a Fekete Péter (= 'der Schuldige, der Letztverantwortliche sein') rührt von dem Kartenspiel für Kinder her, bei dem der Besitz des "Schwarzen Peters" Spielverlust bedeutet, ja sogar die Gewinner zu vorher vereinbarten Streichen berechtigt.

3.2.4. Phraseologismen, die als humorvolle Bildung einen solchen EN in sich fassen, der sonst außerhalb dieser Wendung gar nicht existiert. Hier liegt also ein Scherzname vor, indem aus appellativischen Elementen ein onymischer Ausdruck gebildet wird, ${ }^{34}$ z. B. Nyakfalvára megy [ONG 503] (= 'eine Ohrfeige geben') konstituiert von 'nyak' + 'falva' bzw. Borbéski uraságtól származott [ONG 98] (= 'jm. wird vom vielen Weintrinken übel, er muß sich erbrechen') aus 'bor' + 'be' + 's' + 'ki'.

3.3. Im Zusammenhang mit der Behandlung der etymologisch-historischen Aspekte wäre zu unterstreichen, daß der lexikalische und phraseologische Fonds jeder Sprache einer steter Veränderung und Entwicklung unterliegt. An den politischen, sozio-ökonomischen Fortschritt und die Bereicherung der Kultur knüpfen sich neue Assoziationen und Konnotationen, so daß ständig neue Phraseologismen und phraseologische Bedeutungen entstehen, wohingegen andere Redensarten der Vergessenheit anheimfallen bzw. an die Peripherie der Sprache gedrängt werden. Der erst in den letzten Jahrzehnten aufgekommene Ausdruck Parkinson törvénye ${ }^{35}$ ('Parkinsons Ge- 
setz') verweist auf die von C. Northcote Parkinson in seinem Buch "Parkinson's Law, the Pursuit of Progress" (Boston 1958) mit witziger Ironie aufgestellte Regel, daß bürokratische Arbeit in Behörden und Unternehmen so stark ausgedehnt werde, bis sie die zur Verfügung stehende Zeit ausfüllt.

Ein Teil der phraseologischen Neubildungen behauptet sich fest im Sprachgebrauch, während andere nur als okkasionelle Bildungen oder kurzlebige Modeausdrücke anzusehen sind. Z. B. Bermuda-háromszög ${ }^{36}$ (= 'unlösbares, kompliziertes Rätsel'). Hierher kann man wohl auch die jugendsprachliche Wendung Zolihoz megy ${ }^{37}$ (= 'auf Toilette gehen') zählen.

Der neuentstandene umgangssprachliche Ausdruck Gorbacsov-fröccs (= 'Sodawasser') - wortwörtlich: 'Gorbatschow-Gespritzter' - deutet auf die Maßnahmen zur Bekämpfung des Alkoholismus in der Sowjetunion hin und enthält den Namen des Generalsekretärs des ZK der KPdSU.

Anhand dieses letzteren Beispiels leuchtet ein, daß für die phraseologische Sprachgestaltung auf diesem Gebiet die Vorliebe für Humor sowie irreale Ubertreibung besonders charakteristisch sind. Dies bezieht sich nicht nur auf die Neubildungen: valamikor Ádám nốtlen korában [ONG 34] (= 'schon lange her'). Ab und zu stößt man sogar auf paradoxe Formulierungen, z. B. Ponciustól Pilátusig szaladgál ${ }^{38}$ (= 'von Pontius zu Pilatus laufen, d. h. erfolglos von einem zum anderen laufen'). Diese Redensart scheint auf den ersten Blick barer Unsinn zu sein: 'Pontius' und 'Pilatus' ist der Name einer Person. Der römische Statthalter Pontius Pilatus schickt den gefangenen Jesus zu König Herodes, damit dieser ein Urteil über ihn ausspricht, und der schickt ihn zu Pilatus zurück, daß dieser ihn selbst verurteilen soll. ${ }^{39}$

Die Phraseologismen mit EN sind im Laufe ihrer Entwicklung of t einem semantisch-stilistischen Wandel ausgesetzt. Die Konstruktion Európa beteg embere ${ }^{40}$ bezog sich ursprünglich lediglich auf die Türkei, heute kann sie jedoch in bezug auf einen beliebigen armen kapitalistischen Staat verwendet werden. Oder die Wendung kiverte a Szent Antal tüze [ONG 45] bezeichnete früher lediglich eine Hautkrankheit, die Gesichtsrose (lat. erysipelas), während sie heute darüber hinaus eher ein vom Alkoholgenuß gerötetes Gesicht, einen betrunkenen Zustand umschreibt. ${ }^{41}$

4. Im weiteren, nach der obigen Bestandsaufnahme und einem genetischetymologischen Uberblick des untersuchten phraseologischen Mikrosystems, 
wollen wir nun beleuchten, welche Klassen von EN als phraseologische Konstituenten in der ungarischen Gegenwartssprache besonders produktiv sind. $^{42}$

4.1. Im Hinblick auf mehrere Sprachen wurde schon an vielen Stellen konstatiert, daß die Anthroponyme als phraseologische Strukturelemente die bevorzugte Eigennamenklasse bilden. ${ }^{43}$

4.1.1. Die am stärksten vertretene Gruppe der onymischen phraseologischen Konstituenten machen im Ungarischen zweifellos die Vornamen aus, wobei die vor allem früher sehr verbreiteten männlichen Rufnamen dominieren. Aufgrund des exzerpierten Materials kann festgestellt werden, daß in den anthroponymischen Redensarten 'Pál', 'János', 'Mihály', 'Péter' und 'István' an vorderer Stelle stehen, was mit der Häufigkeit dieser Namen im Einklang steht. ${ }^{44}$ Vgl. otthagyja, mint szent Pál az olăhokat [ONG 539] (= 'jn. unerwartet verlassen, im Stich lassen') bzw. olyan, mint vak János [ONG 314] (= 'sehr unglücklich'). Mit ihrer außerordentlich hohen Frequenz ist zu erklären, daß sie teilweise schon als Gattungsnamen gebraucht werden: z. B. "De hát ez mind kismiska a lốcsei földekhez képest. Mert hát a lốcsei földben terem a világ legjobb és legnagyobb szemú borsója." (Mikszáth Kálmán: A fekete város. Budapest, 1983. S. 78) ("Aber alles das war nur ein Pappenstiel im Vergleich zu den Feldern um Leutschau. Auf den Leutschauer Feldern wuchs nämlich die beste und größte Erbse der Welt." Kálmán Mikszáth: Die schwarze Stadt. Budapest. Corvina Verlag, 1963, S. 116. Ubers. Géza Engl). Andererseits ist zu vermerken, daß weibliche Vornamen, wenn man die Anzahl der vorkommenden PN wie auch die der Wendungen betrachtet, im Bestand ungarischer Phraseologismen wesentlich seltener anzutreffen sind, vgl. Éva lányai ${ }^{45}$ (= 'die Frauen').

Die neuesten, erst in den letzten Jahrzehnten/Jahrhunderten in Mode gekommenen Vornamen fehlen im phraseologischen Sprachgebrauch des Ungarischen fast gänzlich.

4. 1.2. Die phraseologischen Wendungen mit Familiennamen stehen hinter der oben angeführten Gruppe weit zurück, z. B. úgy jấr, mint a Murányi kutyája [ONG 487] (= 'starken Durchfall haben').

Im Vergleich zu den anderen Sprachen fällt auf, daß in den ungarischen Phraseologismen relativ viele weibliche Nachnamen vertreten $\operatorname{sind}^{46}, z$. B. 
másról beszél, mint Bodóné, mikor a bor árát kérik [ONG 89] (= 'jd. spricht an etw. vorbei, lenkt das Gespräch auf einen anderen Gegenstand').

4. 1.3. Komplette, vollständige Personennamen (d.h. Vor- und Nachnamen) tauchen in den ungarischen Phraseologismen noch seltener auf. Z. B. Kis Pista leánya [ONG 367] (= 'Frau von auffällig kleinem Wuchs').

4.1.4. Einige ungarische Redensarten reflektieren Namen von Gottheiten: Fortuna rámosolyog/rákacsint vkire ${ }^{47}$, nach 'Fortuna', der römischen Göttin des Glücks und des Zufalls.

4.1.5. Tiereigennamen können sich hie und da gleichfalls in ungarischen Wendungen widerspiegeln, z. B. (ebbe) belelépett a Csákó [ONG 120] (= 'Speise mit viel Milch/Butter') - Csákó = Name einer Kuh.

4. 2. Den toponymischen Konstruktionen kommt im Ungarischen - im Vergleich zu den anthroponymischen - eine bescheidenere Rolle zu.

4.2.1. Hier überwiegen die Phraseologismen mit Namen von Städten und Dörfern, wobei die ungarischen Ortsnamen den Vorrang haben: jól áll, mint Szeged vizkor [ONG 618] (= 'jd. ist in Not, jm. geht es schlecht'), aber auch ausländische Städtenamen kommen vereinzelt vor: Rómában van [ONG 580] (=1. 'jd. liegt im Kindbett', 2. 'jd. ist verstummt').

4. 2. 2. Ländernamen werden im Bestand ungarischer Phraseologismen etwas seltener wiedergegeben, vgl. annyit ér, mint Németországban egy niksz [ONG 497] (= 'etw. ist nichts wert').

4. 2.3. Bezeichnungen von geographischen Landschaften, Regionen sind in ungarischen Redensarten selten enthalten, vgl. nem adná egész Bánátért [ONG 69] (= 'jd. würde etw. für nichts in der Welt hergeben').

4. 2.4. Hydronyme sind in ungarischen Phraseologismen auch nicht sehr zahlreich vertreten, vgl. zavaros, mint a Maros [ONG 468] (= 'etw. ist sehr trüb').

4.2.5. Namen von Felsen und Bergen als phraseologische Komponenten finden sich noch sporadischer, vgl. Szkülla/Scylla és Karübdisz/Charybdis között ${ }^{48}$ (= 'zwischen Scylla und Charybdis, d. h. sich zwischen zwei gleich großen Gefahren oder Unannehmlichkeiten befinden, in auswegloser Lage sein') bzw. annyi, mint a Mátra szele [ONG 469] (= 'viel').

4.2.6. Astronomische EN als phraseologische Strukturelemente sind im Ungarischen weitgehend unproduktiv, vgl. olyan nehéz, mint a Göncölszekér [ONG 242] (= 'etw./eine Last ist sehr schwer'). 
4.3. Das Spektrum der Phraseologismen, die sonstige Arten von EN beinhalten, ist äußerst begrenzt, vgl. úgy néz ki, mint a Himnuszban a balsors [ONG 284] (= 'ein erbärmliches, armseliges Außeres haben').

5. Aus dem bisher Gesagten geht deutlich hervor, daß viele EN in Phraseologismen nur bedingt als solche angesehen werden können, weil die Verbindung mit ihrem primären Denotat of tmals verlorengegangen ist. Diese Beziehung läßt sich nur mit Hilfe einer tiefgründigen etymologischen Analyse erschließen. Die individualisierende Funktion der EN wird bei der Phraseologisierung zumeist eingebüßt. Die ursprüngliche Hauptfunktion - Konkretisierung und Individualisierung - tritt in den Hintergrund, während die semantische Charakteristik der Phraseologismen in den Vordergrund rückt. ${ }^{49}$

Dieser Vorgang der semantischen Umwandlung wird von Qualitätsveränderungen begleitet, wobei der EN neue, ihm sonst nicht eigene Qualitäten erhält. Es wäre also zu sagen, daß die EN neben ihrer pragmatischen Funktion in den Phraseologismen vielfach noch ein "sekundäres Dasein" als Appellativa führen können. ${ }^{50}$ Die allgemeinste und relevanteste Eigentümlichkeit wird also durch die Spezifik der Phraseologisierung der EN charakterisiert.

5.1. Zunächst wollen wir die potentiellen Wege der semantischen Umdeutung ins Auge fassen. 51

5.1.1. Die Metapher stellt im Ungarischen die typischste Art der Sinnübertragung dar. Z. B. Szodoma és Gomorra ${ }^{52}$ (= Sodom und Gomorrha, d. h. ein Ort der größten Unmoral'). Als Resultat der metaphorischen Umdeutung haben sich die EN von ihrer individualisierenden Funktion entfernt und wurden neben den denotativ-signifikativen Bedeutungen mit konnotativen Komponenten bereichert.

5. 1.2. Der metonymische Gebrauch des onymischen Elements bildet die andere Möglichkeit der Phraseologisierung des ENs. (Im Vergleich zur Metapher kommt diesem semantischen Prozeß in der ungarischen Sprache eine relativ untergeordnete Rolle zu.) Diese Gruppe der Phraseologismen wird durch die Ubertragung der Namensbezeichnung auf verschiedene Gegenstände konstituiert. Die metonymische Umdeutung der onymischen Ausdrücke kann aufgrund des realen Zusammenhangs oder der Berührung von 
Erscheinungen vor sich gehen, die den Inhalt des Basis-ENs und die Bedeutung seiner Verbindung benennen. Vgl. Lórinc van a dinnyében [ONG 446] (= 'Melone schlechter Qualität [nach dem 10. August]').

5.2. Aus unserem Belegmaterial geht hervor, daß die Realisierung der metaphorischen oder metonymischen Bedeutungsveränderung meistens nicht spontan, nicht zufällig erfolgt. Die "Chance" der EN, einer semantischen Umbedeutung ausgesetzt zu werden, ist unterschiedlich. Dabei können drei Faktoren im Vordergrund stehen (die wiederum nicht verabsolutiert werden dürften):

5.2.1. Faktor der Häufigkeit des Vorkommens des ENs. ${ }^{53}$ Die einst sehr häufigen (männlichen) Rufnamen wurden unter bestimmten Umständen seit jeher auch als Appellativnamen benutzt, so daß sie als günstiger Boden für die Bildung von Phraseologismen dienten.

5.2. 2. Der phonetische Faktor bewirkt in gewissen Fällen eine willkürliche Phraseologisierung des ENs ${ }^{54}$, vgl. ami másé, nem Tamásé [ONG 660] (= 'jd. darf nicht anfassen, was nicht ihm gehört'), wobei der Ausdruck auf dem Reim másé - Tamásé aufbaut.

5.2.3. Das Wortspiel übt bei der Phraseologisierung von EN im Ungarischen eine beachtliche Funktion aus. Die so entstandenen Konstruktionen zeichnen sich durch eine überaus hohe Expressivität aus.

Hierbei lassen sich zwei spezifische Typen herausstellen:

- Namenscherze, d. h. Phraseologismen, deren Bedeutung durch das Spiel mit einzelnen Namen oder Namenbestandteilen zustande kommt, indem etwa formal gleiche oder ähnliche Elemente lediglich aufgrund des äußeren Gleichklangs in eine semantische Beziehung gebracht werden. In diesen Fällen wird von echten EN ausgegangen ${ }^{55}$, vgl. Törtelre ment [ONG 682] (= 'etw. zerbricht') fußt z. B. auf der Ähnlichkeit des Ortsnamens 'Törtel' und des Verbs (el)tör(ik) (= 'zerbrechen').

- Scherznamen, d. h. wenn eine appellativische Bedeutung in eine Namensstruktur gebracht wird, also kein echter EN vorliegt ${ }^{56}$, vgl. Fillent regimentjébe való [ONG 213] (= 'Lügner'), konstituiert wohl aus dem Verb füllent/fillent ('lügen').

Die soeben dargestellten Arten der "phraseologischen Spiele" sind in der ungarischen Gegenwartssprache als ausgesprochen produktiv anzusehen und fungieren vornehmlich als Euphemismen für verpönte Begriffe. Unsere 
Betrachtungen zeugen davon, daß der Euphemismus im Ungarischen geradezu eines der kennzeichnendsten Merkmale der onymischen Phraseologismen ist. Infolge der Asymmetrie des phraseologischen Systems überwiegen die Einheiten mit negativem Bedeutungsinhalt sowieso, was hier besonders prägnant zum Ausdruck kommt. Wortspiel und Euphemismus hängen also bei den onymischen Redensarten des Ungarischen eng zusammen, ihre Anzahl ist alles andere als gering. 57

6. In den obigen Ausführungen kam schon zum Ausdruck, daß bei den EN als phraseologische Konstituenten an die Stelle ihrer individualisierenden Funktion in der Regel andere semantische Qualitätsmerkmale treten. In dieser Dimension wollen wir nun das Funktionieren der EN im Bestand phraseologischer Wendungen erfassen.

6. 1. Einer der semantischen Wesenszüge der behandelten phraseologischen Subgruppe äußert sich in der Bedeutungsintegration. Unsere Phraseologismen verfügen über eine stabile Bedeutung, die teilweise primär interpretierbar, teilweise auch übertragen sein kann. Im ersten Falle bewahren die EN innerhalb der Redensart ihren Eigennamencharakter, d. h. bleiben onymisch, z. B. (úgy) all, mint a Sion hegye [ONG 596] (= 'fest, sicher, unerschütterlich dastehen'). Im zweiten Fall - und dabei handelt es sich um die Mehrheit der Bildungen - sind die onymischen Elemente des Phraseologismus deonymisiert, nur genetisch als solche zu betrachten ${ }^{58}$ z. B. Pilátus konyhája [ONG 558] (= 'Toilette').

Viele Linguisten vertreten die Ansicht, daß der EN gleichzeitig die konkreteste und abstrakteste Kategorie der Sprache sei. ${ }^{59}$ Mit dem Merkmal der Konkretheit haben wir es dann zu tun, wenn die benennende Funktion dominiert (wenn der Name jn. oder etw. identifiziert): Das Merkmal der Abstraktheit wird dann bestimmend, wenn der Name kein determiniertes, konkretes Denotat bezeichnet, sondern sich auf beliebige Mitglieder einer gewissen Kategorie, einer Gruppe von Lebewesen beziehen kann. Dieser Dualismus ist ein typisches Charakteristikum der EN. Welche Seite gerade realisiert wird, hängt immer von der jeweiligen Situation, vom sprachlichen Kontext ab. 
In diesem Sinne werden wir uns weiter der Erschließung der Funktionen der phraseologisierten EN zuwenden, wobei wir uns - aus praktischen Uberlegungen - in erster Linie auf die Anthroponyme konzentrieren.

a) Benennende Funktion

Als die phraseologische Konstruktion entstanden ist, war das Verhältnis zwischen dem Träger des PNs und der Wendung für die Sprecher klar. Seitdem ist der kulturgeschichtliche, sozio-ökonomische etc. Hintergrund zumeist verblaßt, so daß der PN heute nur noch das Geschlecht signalisiert. ${ }^{60} \mathrm{Vgl}$. Magda Magdának, Magda az egész világnak [ONG 459] (= 'wenn eine Frau etw. erfährt, erzählt sie es einer anderen weiter, und schließlich wird es allgemein bekannt').

b) Charakterisierende Funktion

Bei den Redewendungen dieser Art liegt der Anlaß zum erweiterten Gebrauch des ENs offen zutage: Das individuelle Vorbild, der Prototyp des ENs hat sich als Träger einer bestimmten Eigenschaft dem allgemeinen Bewußtsein eingeprägt, und der Name ist zur symbolischen Charakterisierung dieses Eigenschaftsbegriffs geworden. Dieses Phänomen hängt wohl mit den verallgemeinernden, typisierenden Charakterzügen der EN zusammen. ${ }^{61}$ Im Ungarischen gibt es nicht wenig Vornamen, an die sich im Laufe der Zeit verschiedene Bedeutungen knüpften, vgl. 'Balázs' = 'dumm' $\rightarrow$ adósa Balázsnak [ONG 68] (= 'recht dumm'), 'Antal' = 'einfältig, unzuverlässig' $\rightarrow$ Antal a fejed [ONG 45] (= 'du bist einfältig, unzuverlässig'), 'Bence/Orbán' = 'trunksüchtig' - feltette Bence sapkáját [ONG 80] bzw. feltette az orbán süvegét [ONG 519] (= 'jd. ist betrunken'). 62

C) Pronominale Funktion

Da sich derselbe EN auf eine unbegrenzte Anzahl von Denotaten beziehen kann, ist es nicht zufällig, daß EN im Bestand der Phraseologismen als Gattungsnamen stehen könnnen. ${ }^{63}$ In der Wendung (hogy) el ne menjen a Péterkéje [ONG 557] (= 'jd., ursprünglich eine schwangere Frau, hat Wünsche, die man erfüllen sollte') bedeutet 'Péterke' einfach 'Kind'.

d) Deiktische Funktion

Diese Erscheinung liegt vor, wenn der EN als phraseologische Komponente die Eigenschaften, die typischen Merkmale des korrelierenden Denotats nicht nennt, sondern auf seine Abweichung vom gewöhnlichen Durch- 
schnitt indirekt hindeutet. ${ }^{64} \mathrm{Vgl}$. olyan, mint a Pilátus macskája [ONG 558] (= 'müde, blaß nach einer durchzechten Nacht').

e) Stilistische Funktion

Sie hängt bei den onomastischen Phraseologismen sehr of t mit Reim oder Alliteration zusammen. ${ }^{65}$ vgl. most légy okos, Domokos [ONG 149] (= 'jetzt ist guter Rat teuer').

Aus den obigen Ausführungen wird ersichtlich, daß die EN im Bestand ungarischer Phraseologismen sowohl spezifische onomastische (benennende, charakterisierende, pronominale) als auch allgemein-sprachliche (deiktische, stilistische) Funktionen ausüben können.

7. In Anbetracht der paradigmatischen Eigenschaften der EN als Strukturelemente ungarischer Phraseologismen ist zu konstatieren, daß sie im Vergleich zu den Gattungsnamen durchaus begrenzt sind.

7.1. Infolge der Phraseologisierung werden den EN auch verschiedene appellativische Charakteristika zuteil, z. B. die Fähigkeit, in ihrer semantischen Struktur mehrere Bedeutungen zu integrieren. Für das Englische und das Deutsche wird der Anteil der Polysemie bei den onymischen Phraseologismen auf nicht ganz fünf Prozent geschätzt ${ }^{66}$, was unter Umständen auch für das Ungarische als Orientierungsgröße dienen kann, z. B. Balázs vitéze [ONG 68] $=1$. 'Schuljunge, der am Basiliustag betteln geht' 2. 'feiger, schlechter Soldat' 3. 'dünner, schmächtiger Mann'.

7.2. Die Synonymie zeigt auch das "sekundäre Dasein" der EN im Bestand von phraseologischen Konstruktionen. Das bringt sie den Gattungsnamen nahe und unterscheidet sie vom EN im eigentlichen Sinne. Für die synonymen Phraseologismen ist generell die Realisierung nahezu identischer Bedeutungsinhalte in unterschiedlichen bildhaften Ausdrucksstrukturen kennzeichnend. ${ }^{67}$ Unsere Untersuchung hat verdeutlicht, daß das gleiche auch für die onymischen Redensarten des Ungarischen gilt.

Dabei lassen sich vier qualitative Typen der synonymischen Verhältnisse erkennen:

a) Einem Phraseologismus mit EN steht ein Einwortlexem gegenüber, z. B. úgy néz, mint Pilátus macskája [ONG 558] - kancsalit (= 'schielen'); 
b) Eine onymische Redensart korreliert mit einem Phraseologismus, der keinen EN als Strukturkomponente hat, z. B. jól beszedett Krisztus vérébõl [ONG 394] - felöntött a garatra (= 'sich vollaufen lassen');

c) Synonymie jeweils innerhalb der Gruppe der anthroponymischen bzw. der toponymischen Phraseologismen, z. B. megtért Abrahám kebelébe [ONG 32] - Pilátusra vicsoritja a fogát [ONG 558] (= 'sterben');

d) Relativ selten korrespondieren anthroponymische Phraseologismen mit toponymischen Wendungen, z. B. öreg, mint a szent Péter szamara [ONG 556] - vénebb Paksnál [ONG 538] (= 'recht alt').

7.3. Da sich an den onymischen Kern der Redensarten stets dieselben Assoziationen und Konnotationen knüpfen, ist die Antonymle bei den Phraseologismen mit EN nicht sehr stark ausgeprägt. Vgl. aber gazdag, mint (egy) Krốzus $^{68}$ (= 'äußerst reich') - szegény, mint Lázár [ONG 425] (= 'sehr arm'). Anhand dieses Beispiels könnte man annehmen, daß die semantische Polarität bereits durch die Adjektive gazdag ('reich') bzw. szegenny ('arm') determiniert ist. Andererseits ist aber festzustellen, daß schon 'Krőzus' ${ }^{69}$ und 'Lázár' ${ }^{70}$ selbst zu Appellativnamen wurden, bei denen man die ausgedrückten Eigenschaften auch ohne die dazugehörenden Adjektive assoziiert. 7.4. Die Variantenbildung bei den onymischen Phraseologismen verdient ebenfalls besondere Aufmerksamkeit. Uns interessieren vor allen Dingen die Varianten, die durch Veränderungen im lexikalischen Bestand der Konstituenten zustande kommen. Aus dieser Sicht kann man zwei separate Möglichkeiten herausstellen:

- Wechsel der nicht-onymischen Strukturelemente: elvitte/elragadta a Szent Mihály lova [ONG 481] (= 'sterben'). Wie ersichtlich, beruht hier der mögliche Wechsel auf einem semantischen Faktor, nämlich auf der semantischen Nähe der korrelierenden Lexeme oder auf ihrer Zugehörigkeit zu derselben thematischen Gruppe. Manchmal tauchen aber auch kompliziertere Fälle auf, wo nicht nur die einzelnen phraseologischen Konstituenten variieren, sondern ihre lexikalisch-grammatischen Fragmente. Dies könnte im Grunde genommen als Grenzfall zwischen Varianz und Synonymie angesehen werden. ${ }^{71}$ Da hier aber die gemeinsame lexikalische Invariante erhalten bleibt und bloß die bildhafte Grundlage modifiziert wird, zählen wir diese Erscheinung zur Varianz. Vgl. elköltözött Abrahámra vicsorkodik [alle: ONG 32] (= 'sterben'). 
- Es variieren die onymischen Komponenten. Hierbei erfolgt die Varianz nicht auf semantischer Basis, was mit verschiedenen Faktoren im Zusammenhang stehen kann ${ }^{72}$, beispielsweise die Identität der symbolischen Charakteristik: Bandi/Pali/Pista/Samu legyen a nevem, ha... [ONG 69, 539, 559, 589] (= 'scherzhafte Beteuerung') bzw. bejárja Tolnát-Baranyat/ungot-berket ${ }^{73}$ (= 'weite Gebiete [vergeblich] durchwandern').

8. Der appellative Charakter der phraseologisierten EN wirkt sich natürlich auch auf ihre syntagmatischen Beziehungen aus. ${ }^{74}$

8.1. Normativer Gebrauch der EN mit unbestimmtem Artikel (in klassifizierendem Sinn): vki nem egy Adonisz ${ }^{75}$ (= 'jd. ist nicht gerade ein Adonis, d. h. nicht schön').

8.2. Der idiomatisierte EN kann regulär in der Opposition Singular - Plural auftreten: "Azt beszélik, a régi igazgató csupa fejbólintó jánossal vette körül magát... Erről kérdeztem Sipos Mihályt, aki a fejbólintó jánosokat tagadta, de azt elismerte, hogy egyes vezetô posztokra nem ültetett időben alkalmas embereket." ("Es heißt, daß der alte Direktor lauter Jasager um sich versammelt hätte... Ich fragte Mihály Sipos danach, der zwar bestritt, daß sie alle nur Jasager gewesen seien, jedoch zugab, daß einige Führungsposten nicht rechtzeitig mit geeigneten Leuten besetzt worden wären.") (Magyar If júság, 15. Mai 1987, S. 9.)

8.3. Im Rahmen ein und desselben Kontextes kann ein eigentlicher EN und ein phraseologisierter EN auftreten; vgl. "Nem Joseph Judge, a National Geographic egyik főszerkesztője volt az elsố hitetlen Tamás." ("Joseph Judge, einer der Chefredakteure der Zeitschrift 'National Geographic', war bei weitem nicht der einzige ungläubige Thomas.") (Népszabadság, 1. Aug. 1987, S. 11.)

8.4. Bei vielen phraseologisierten PN ist der Verlust des Genusmerkmals zu beobachten, d. h. die Redensart kann sich auf Vertreter beider Geschlechter beziehen, unabhängig von der ursprünglichen Zugehörigkeit des PNs. Beispielsweise kann die Wendung palira vesz vkit [ONG 539] (= 'jm. einen Bären aufbinden, jn. betrügen') auch in bezug auf ein weibliches Lebewesen benutzt werden; vgl. "Volt egy állati rendes és nagyon gazdag svájci fiú, ha jól emlékszem, Clausnak hívták. 1985 ôszén ismertem meg a Várban. Nagyon tetszettem neki. Valahogy úgy sugárzott róla, hogy nyugodtan elmehetek vele, nem fog palira venni." ("Da war ein Junge aus der Schweiz, tierisch in 
Ordnung und unheimlich reich, wenn ich mich richtig erinnere, hieß er Claus. Im Herbst 1985 hatte ich ihn auf der Burg kennengelernt. Irgendwie war ihm anzusehen, daß ich ruhig mit ihm ausgehen konnte, daß er mich nicht ausnutzen würde.") (Zombori Attila: Szex-piaci körséta. Budapest 1986, S. 47.) 8.5. Manche anthroponymischen Phraseologismen können sowohl in Verbindung mit Lebewesen als auch für unbelebte Denotate stehen. Die Konstruktion Róbert bácsi (= wortwörtlich: 'Onkel Robert') umschreibt eine gutherzige, großzügige Person und zuweilen auch eine wohltätige Institution; vgl. "A 'Róbert bácsi' itt egy Kilencedik sugárúti protestáns egyházközség volt, amely néhány hónappal ezelött, a gazdasági válság súlyosbodása közepette szervezte meg a jómódú hivek pénzén ezt a melegedő- és étkezőhelyet." ("Der 'wohltätige Onkel' war hier eine protestantische Gemeinde in der 9. Avenue, die vor einigen Monaten, als die Wirtschaftskrise gerade ihren Höhepunkt erreicht hatte, mit dem Geld der wohlhabenderen Gläubigen diese Aufwärm- und Verpflegungsstelle einrichtete.") (Kulcsár István: Tudósítás Atlagamerikából. Budapest 1987, S. 96.)

8.6. Die phraseologisierten EN erscheinen immer häufiger mit kleinem Anfangsbuchstaben; vgl. "Nincs már nekem annyi idő́m hátra az életben, hogy még egyszer kiadjam az ötleteimet, Csáki szalmájává, elherdálásra." ("Mir verbleibt nicht mehr so viel Zeit im Leben, als daß ich meine besten Ideen nocht einmal so hergeben, so vergeuden könnte, als Freibeute, an der sich jeder bedienen kann.") (Az Ország-Világ Nyári Magazinja, Juni 1987, S. 15), aber: "Hiába volt igazam, hogy a munkaidővel nem lehet úgy bánni, mint a csáki szalmájával - nem védett meg a demagógiától sem a minisztérium, sem a helyi pártszervezet." ("Zwar hatte ich Recht mit meiner Ansicht, daß man mit der Arbeitszeit nicht umgehen könne, wie mit einer nie versiegenden Quelle, doch schützte mich vor der Demagogie weder das Ministerium noch die örtlichen Parteiorgane.") (Nő́k Lapja, 17. Mai 1986, S. 9.)

8.7. Einige phraseologisierte $\mathrm{EN}$ haben nicht nur ihre onymischen Merkmale verloren, sondern sogar ihren substantivischen Charakter, so daß sie auch Konversionen und/oder Zusammenrückungen unterliegen können und sich dadurch syntagmatish anders verhalten; vgl. "Allj meg, vándor! - szólt rá az Egér. - Nem ilyen hưbelebalázs módjára kell csinálni." ("Halt ein, Wanderer! ermahnte inn die Maus. Du mußt es nicht auf so überstürzte Weise machen.") (Lázár Ervin: A hétfejü tündér. 3. Aufl. Budapest 1973, S. 27.) 
8.8. Es gibt Fälle, wo der onymische Phraseologismus derart als Wortäquivalent aufgefaßt wird, daß bei seiner syntaktischen Verbindbarkeit die wendungsinternen syntagmatischen Beziehungen nicht berücksichtigt werden; vgl. "Nem voltunk mi sem jobbak a deákné vásznánál, a mai gyerekeknél, akiket - úgy mondják - nem lehet fegyelmezni." ("Wir waren auch nicht besser als sie, als die Jugend von heute, von der man sagt, daß sie keine Disziplin habe.") (Szabad Föld, 25. Sept. 1987, S. 20.)

9. Die Auswertung des sprachlichen Materials hat nachgewiesen, daß die onymischen Phraseologismen der ungarischen Sprache im wesentlichen durch dieselben Merkmale gekennzeichnet sind, die auch anderen Wendungen des ganzen phraseologischen Systems eigen sind.

Die hauptsächliche Eigentümlichkeit dieses phraseologischen Mikrosystems kann man so zusammenfassen, daß sowohl die Entstehung der Wendungen als auch ihre grundlegenden systemhaften Eigenschaften durch den Ubergang des ENs in ein "sekundäres Dasein" determiniert werden.

CSABA FÖLDES

\section{ANMERKUNGEN}

1. ERMACENKO, M. N.: Semantiko-grammatiČeskie osobennosti imen sobstvennych (na materiale francuzskogo jazyka). AKD, Moskva 1970;

SUPERANSKAJA, A. V.: Obščaja teorija imeni sobstvennogo. Moskva 1973, S. 261 - 276;

STUPIN, L. I.: O leksičeskom značnii imen sobstvennych. In: Voprosy teorii $\mathrm{i}$ istorii jazyka. Sbornik pamjati B. A. Larina. Leningrad 1969, S. 216 - 224;

TOLSTOJ, N. I.: Ešče raz o "semantike" imeni sobstvennogo. In: Aktual'nye problemy leksikologii. Moskva 1970, S. 201;

GARDINER, A.: Teorija sobstvennych imen. Moskva 1954, S. 8.

2. Z. B.: NAZAROV, Kambarali: Der Eigenname als Element der Lexik und als Komponente von Phraseologismen. In: Namenkundliche Informationen Nr. 34, KMU Leipzig 1978, S. 30 - 33 sowie NAZAROV, Kambarali: Sopostavitel'noe issledovanie frazeologičeskich edinic s onomastičeskim komponentom nemeckogo, anglijskogo i russkogo jazykov. AKD, Moskva 1980 , S. 4. 
3. LEONIDOVA, M. A.: $K$ voprosu o sočetaemosti sobstvennogo imeni vo frazeologičeskich edinicach ( $v$ bolgarskom i russkom jazykach). In: Problemy leksikologii. Sbornik stat'ej. Minsk 1973, S. 64.

4. FLEISCHER, Wolfgang: Phraseologie der deutschen Gegenwartssprache. Leipzig 1982, S. 100.

5. FÖLDES, Csaba: Phraseologismen mit Anthroponymen in der deutschen und ungarischen Gegenwartssprache. In: Budapester Beiträge zur Germanistik (im Druck).

6. O. NAGY, Gábor: Magyar szólások és közmondások. 4. Aufl., Budapest 1985.

7. Vgl. MAYER, Klára-Irén: A magyar szólásokban és közmondásokban előforduló tulajdonnevekről. In: Névtani Értesítő 9, Budapest 1984, S. 84.

8. Vgl. den Hinweis von O. NAGY, Gábor: Mi fán terem? Magyar szólásmondások eredete. Budapest $1979^{3}$, S. 113 f. auf ERDEL YI, János: Magyar közmondások könyve 1851, S. 84; In der Arbeit von BERNÁTH, Béla: A szerelem titkos nyelvén. Erotikus szólások és folklórszövegek magyarázata. Budapest 1986, S. 33 - 46 findet man eine eigenartige Deutung für diese Wendung, der aber ebenfalls eine appellativische Basis zugrunde liegt.

9. TOTH, Béla: Szájrul szájra. A magyarság szállóigéi. Budapest 1895, S. 15.

10. Siehe ausführlicher bei KERTÉSZ, Manó: Szokásmondások. Nyelvünk múvelốdéstör téneti emlékei. Budapest o. J. S. 90.

11. A magyar nyelv értelmező szótára. Szerk. az MTA Nyelvtudornányi Intézete. 4. Aufl., Budapest 1984.

12. Új Magyar Lexikon. Band 4. Budapest 1962, S. 305.

13. DUDEN. Etymologie. Herkunftswörterbuch der deutschen Sprache. Bearbeitet von G. Drosdowski, P. Grebe und weiteren Mitarbeitern der Dudenredaktion. DUDEN, Band 7. Mannheim/Wien/Zürich 1963, S. 297.

14. Vgl. MANUŠKINA, G. P.: Frazeologičeskie edinicy s komponentom "imja sobstvennoe" v sovremennom anglijskom jazyke. AKD, Moskva 1973, S. 15.

15. Siehe Anm. 14.

16. GARIFULIN, L. B. - ANTONOVA, M. K.: Ustojčivye socětanija s antroponimami (v sopostavitel'nom plane). In: Frazeologija, vyp. 1, Celjabinsk 1973, S. 155.

17. Vgl. O. NAGY, Gábor: (siehe Anm. 8) S. 112; 
Hierbei verweisen wir auf die ganz neuartige Deutung von BERNÁTH, Béla: (siehe Anm. 8) S. $25 \mathrm{ff}$, nach der 'Marci' euphemistisch für das männliche Glied und 'Heves' für das Geschlechtsorgan der Frau stehe.

18. Sechs verschiedene Erklärungen für die Fügung enthält der Beitrag in: Magyar Nyelvör 29 (1900)1. S. 83 - 85.

19. Vgl. FÖLDES, Csaba: Eigennamen in deutschen phraseologischen Redewendungen. Eine etymologische und semantisch-stilistische Analyse. In: Muttersprache 95 (1985) 3 - 4. S. 176; sowie FÖLDES, Csaba: Anthroponyme als Strukturkomponenten deutscher Phraseologismen. In: Zeitschrift für germanistische Linguistik 15 (1987)1. S. 5 f.; sowie FÖLDES, Csaba: (siehe Anm. 5).

20. Vgl. "Reggel azután az újságokból ér tesültem róla, hogy harminc benzinpalackot - a nálunk is ismert Molotov-koktélt - robbantották az éjjel, s jórészét a Piazza Cavour környékén." ("Am Morgen danach erfuhr ich aus der Zeitung, daß man in der Nacht 30 mit Benzin gefüllte Flaschen Molotov-Cocktails wie sie auch bei uns bekannt sind - hatte hochgehen lassen, und die meisten davon in der Gegend der Piazza Cavour.") (Kardos G. György: Római pillanatok. In: Körkép 86, S. 251.)

21. Vgl. "Jóval több annál, semmint, hogy ki a szebbik közülük a ködös Albionban..." ("Es war viel mehr als nur die Frage, wer die Schönste von ihnen sei...") (Az Ország-Világ Nyári Magazinja, Juni 1987, S. 14.)

22. Vgl. "Miként meséli, az ér tő szakma befogadta ôt, a már-már élethosszig vidéki létre szoritott szinészt Thália szentélyébe, de elszomorodva kell arra gondolnom, hogy a közönség soha nem értékelte igazi rangján Siménfalvy Sándort." ("Wie er erzählt, nahm zwar die ganze Fachbranche ihn, den fast sein ganzes Leben lang zu einem Dasein in der Provinz gezwungenen Schauspieler, in das heilige Reich der Thalia auf, aber mit Bedauern muß ich daran denken, daß das Publikum Sándor Siménfalvy niemals in der Weise geschätzt hatte, wie er es verdient hätte.") (Magyar Ifjúság, 12. Juli 1987, S. 6.)

23. Vgl. "Egy hivatalszervezet, amely sok tizezres vagy sok százezres adattal, ügyirattal dolgozik, körülbelül a tizenkilencedik század elejének megfelelő technológiával pörgeti az ügymenet orsóin Ariadne véget nem érố jogszabályfonalait." ("Ein Amt, das mit vielen zehntausend oder hunderttausend Daten und Schriftstücken arbeitet, wickelt mit einer Technologie, wie sie ungefähr zu Beginn des vergangenen Jahrhunderts üblich war, die Ariadne-Fäden nicht enden wollender Rechtsvorschriften auf den Spulen des Geschäftsganges ab.") (Népszabadság, 31. Juli 1987, S. 4.)

24. Vgl. "Sok a beérkezó kötet, kevés az alkalmazott, igy hát az is elő́fordul, hogy hónapokig, de talán esztendeig is Csipkerózsikaálmát alussza egy-egy szakkönyv, tudományos munka." ("Viele Bücher treffen ein, aber es gibt nur wenig Angestellte, und so kann es schon mal vorkommen, daß ein Fachbuch oder eine wissenschaftliche Arbeit monate-, vielleicht 
jahrelang einen Dornröschenschlaf schläft.") (Népszabadság, 10. Juni 1987, S. 1.)

25. BÉKÉS, István: Napjaink szállóigéi. 2. verb. und erw. Aufl. I - II. Budapest 1977, S. 607.

26. HERNADI, Miklós: Közhelyszótár. Budapest 1976, S. 341.

27. Vgl. BÉKÉS, István: (siehe Anm. 25), S. 289; bzw. "- Meg azért is szoktak irigyelni minket, hogy mekkora Don Juanok vagyunk - felém fordul." (Moldova, György: A pénz szaga. Riport a kamionsoförökről. Budapest 1986, S. 223.)

28. BÉKÉS, István: (siehe Anm. 25), S. 449.

29. Die Herleitung der Wendung nach MELICH, János: Német vendégszók. In: Magyar Nyelvốr 24 (1895), S. 251.

30. RÖHRICH, Lutz: Lexikon der sprichwörtlichen Redensarten. Freiburg i.B./Basel/Wien 1973, S. 952.

31. Vgl. "A régi szimándli embernek nemcsak a csúfolkodást kellett eltứrnie, de akárhányszor mint valóságos búnössel bántak el vele." (Ráth-Végh, István: Szerelem, házasság. Budapest $1975^{3}$, S. 411.)

32. Vgl. "Bájos lejterjakabot - azaz félreforditást - találtam lapjuk múlt évi 51. számában a Miért szép? rovatban." (Élet és Tudomány, 31. Jan. 1986, S. 130.)

Vgl. zur Wendung ebenfalls: FÖLDES, Csaba, Biblische Phraseologismen im Deutschen und Ungarischen. In: Germanistisches Jahrbuch DDR UVR. Hrsg. von Sabine Dallman. Lektorat für deutsche Sprache und Literatur beim Kultur- und Informationszentrum der DDR in Budapest, Bd. 5 (1986), S. 182; bzw. BÉKÉS, István: (siehe Anm. 25), S. 654 f.

33. Vgl. FÖldES, Csaba: (siehe Anm. 19) 1985, S. 176 f. sowie 1987, S. 7 f. und FÖLDES, Csaba: (siehe Anm. 5).

34. Vgl. dazu FLEISCHER, Wolfgang: (siehe Anm. 4), S. 104.

35. Vgl. "A Parkinson-törvêny az ENSZ-ben is érvényes: iróasztal iróasztalt szül." (Kulcsár, István: Tudósítás Atlagamerikából. Budapest 1987, S. 18.)

36. Vgl. "Eddigi gyakorlatunkban az ár - támogatás - adó valóságos Bermuda-háromszöggé alakult, amelyben megnehezült a tényleges teljesitmény mérésének a lehetősége, és a teljesitmény alapján álló ösztönző rendszerek múködése." (Nốk Lapja, 11. Juli 1987, S. 5.)

37. KOVALOVSZKY, Miklós: Az ifjúság nyelvéről. In: A mai magyar nyelv. (Cikk- és tanulmánygyújitemény) II. Össz.: Keszler, Borbála. Budapest 1977, S. 38. 
38. Vgl. "S most ez a megkínzott, halálra üldözött, meggyalázott teremtés még maga töri magát Ponciustól Pilátusig, hogy egy ilyen eszeveszett bolondnak a fejét megmentse." (Jókai, Mór: A ló́csei fehér asszony. Budapest 1974, S. 352.)

39. Siehe ebenfalls FÖLDES, Csaba: (siehe Anm. 32), S. 179, und BEKKÉS, István: (siehe Anm. 25), S. 81 .

40. HERNÁDI, Miklós: (siehe Anm. 26), S. 89.

41. Detailliertere Angaben zur Etymologie des Phraseologismus sind zu finden bei O. NAGY, Gábor: (siehe Anm. 8), S. $442 \mathrm{f}$. und besonders bei GALGÓCZI, László: Betegségneveink történetéből: Orbánc 'erysipelas'. In: A Juhász Gyula Tanárképző Főiskola Tudományos Közleményei 1981, I. S. 64 - 74 sowie GALGOCZI, László: Szent Antal tüze. In: IV. Magyar Névtudományi Konferencia, Zalaergerszeg 1986 (im Druck).

42. Vgl. FÖLDES, Csaba: (siehe Anm. 19), S. 9 f. sowie FöldES, Csaba: (siehe Anm. 5).

43. Vgl. für das Deutsche: FLEISCHER, Wolfgang: Eigennamen in phraseologischen Wendungen. In: Namenkundliche Informationen, Nr. 28, KMU Leipzig, 1976, S. 3; FLEISCHER, Wolfgang: siehe Anm. 4), S. 101; FÖLDES, Csaba: (siehe Anm. 19) 1985, S. 177 bzw. 1987, S. 1; FÖLDES, Csaba: (siehe Anm. 5);

für das Englische: GLASER, Rosemarie: Eigennamen in idiomatisierten Phraseologismen des Englischen. In: Namenkundliche Informationen, Beiheft 2 (Studia Onomastica I), KMU Leipzig 1980, S. 28;

für das Englische und Deutsche: OCHSTAT, R. I.: Opyt sopostavitel'nogo analiza frazeologizmov $s$ imenem sobstvennym (na materiale anglijskogo i nemeckogo jazykov). In: Voprosy onomastiki. Samarkand 1971, S. 94 95;

für das Russische und Polnische: LAGINOVIC, Jadviga: Imena sobstvennye v russkoj i pol'skoj frazeologii. AKD Minsk 1978, S. 6;

für das Russische: MOKIENKO, V. M.: Sobstvennoe imja v sostave russkoj frazeologii. In: Ceskoslovenská rusistika 22 (1977), S. 1.

44. Allein im Wörterbuch von O. NAGY, Gábor: (siehe Anm. 6) sind mit Pál 20, János 18, Mihály 16, Péter 15, István 14 Wendungen aufgelistet.

45. Vgl. "A megosztott tudásról, a megosztott Nobel-dijakról, arról a példázatról, melybốl az életpálya során kiviláglik, hogy a alma nem tiltott gyümölcs Éva lányainak sem." (Az Ország-Világ Nyári Magazinja, Juni 1987, S. 14.)

46. Im Wörterbuch von O. NAGY, Gábor: (siehe Anm. 6) befinden sich Phraseologismen mit 22 verschiedenen weiblichen Familiennamen.

47. Vgl. "... s amikor ezt bizonygatják, sietve mindjárt hozzá is fưzik, jobb helyre aligha kacsinthatott volna Fortuna, mint tette az utóbbi fél esztendőben." (Népszabadság, 28. Aug. 1987, S. 6.) 
48. BÉKÉS, István: (siehe Anm. 25), S. 104.

49. Vgl. KUDINA, Elena/STARKE, Günter: Untersuchungen zu Phraseologismen mit Eigennamen im Deutschen im Vergleich mit dem Ukrainischen. In: Wissenschaftliche Zeitschrift der Pädagogischen Hochschule "Karl Liebknecht" Potsdam 22 (1978), S. 188: OCHSTAT, R. I.: O funkcionirovanii sobstvennych imen vo frazeologii sovremennogo nemeckogo jazyka ( $k$ postanovke voprosa). In: Trudy Samarkandskogo Gos. un-ta im. A. Navoi, Novaja serija, vyp. 217 (= Voprosy frazeologii IV), Samarkand 1971, S. 83; NAZAROV, Kambarali: (siehe Anm. 2) 1978, S. 33 - 34; MANUŠKINA, G. P.: (siehe Anm. 14), S. 17 ff.; FÖLDES, Csaba: (siehe Anm. 19) 1987, S. 10 f. und FÖlDES, Csaba: (siehe Anm. 5).

50. MULleR, Ewald: Vornamen als appellative Personenbezeichnungen. Onomatologische Studien zur Wortkonkurrenz im Deutschen. Helsingfors 1929, S. 1.

51. Ähnliches wird z. B. auch für das Deutsche festgestellt von NAZAROV, Kambarali: (siehe Anm. 2) 1978, S. 34 und FÖLDES, Csaba: (siehe Anm. 19) 1987, S. 11.

52 BÉKÉS, István: (siehe Anm. 25), S. 20.

53 Vgl. dazu OCHSTAT, R. I.: (siehe Anm. 49), S. 88; OCHక̌TAT, R. I.: Imja sobstvennoe kak komponent frazeologičeskoj edinicy i kak samostojatel'noe slovo. In: Trudy Samarkandskogo Gos. un-ta im. A. Navoi, vyp. 219, čast' I (= Voprosy frazeologii V), Samarkand 1972, S. 177; KUSLIK, A. M.: $\mathrm{K}$ voprosu o perechode imen sobstvennych $\vee$ imena naricatel'nye. In: Učenye zapiski Leningradskogo Gospedinstituta im. Gercena, t. 189, vyp. 2, S. 162 - 163; MANUŠKINA, G. P.: (siehe Anm. 14), S. 18; LAGINOVIC, Jadviga: (siehe Anm. 43), S. 5; FÖLDES, Csaba: (siehe Anm. 19), 1987, S. 11 f. sowie FÖLDES, Csaba: (siehe Anm. 5).

54. Vgl. dazu KUSLIK, A. M.: (siehe Anm. 53), S. 157; MANUSKKINA, G. P.: (siehe Anm. 14), S. 18; LAGINOVIC, Jadviga: (siehe Anm. 43), S. 5; NAGY, L. János: A nevek szerepe idiómáinkban. (O. Nagy Gábor gyứjteménye alapján). In: IV. Magyar Névtudományi Konferencia, Zalaegerszeg 1986 (im Druck); FÖLDES, Csaba: (siehe Anm. 19) 1987, S. 12 sowie FÖLDES, Csaba: (siehe Anm. 5).

55. Siehe dazu RÖHRICH, Lutz: (siehe Anm. 30), S. 14 und FLEISCHER, Wolfgang: (siehe Anm. 4), S. 104.

56. Vgl. FLEISCHER, Wolfgang: (siehe Anm. 4), S. 104.

57. Vgl. FÖLDES, Csaba: (siehe Anm. 5).

58. FLEISCHER, Wolfgang: (siehe Anm. 4), S. 102 sowie FÖLDES, Csaba: (siehe Anm. 19) 1985, S. 178 und 1987, S. $13 \mathrm{f}$.

59. SUPERANSKAJA, A. V.: (siehe Anm. 1); NIKONOROV, V. A.; Imja i obščestvo. Moskva 1974; MAGAZANIK, E. B.: Onomatopoėtika ili "go- 
vorjaščie imena" v literature. Taškent 1978, siehe dazu CSIGE, Katalin: Orosz közmondásokban és szólásmondásokban szereplő személynevek vizsgálata. In: Acta Academiae Paedagogicae Nyíregyháziensis, Tom 10/E (= Russzisztika), 1985, S. 143.

60. Siehe bei CSIGE, Katalin: (siehe Anm. 59), S. 143.

61. Vgl. MULlLER, Ewald: (siehe Anm. 50), S. 6; CSIGE, Katalin: (siehe Anm. 59), S. 144 - 145; FÖLDES, Csaba: (siehe Anm. 19) 1987, S. 14; sowie STEPANOVA, L. I.: Funkcii imeni sobstvennogo v sostave frazeologičeskoj edinicy. In: Vestnik Leningradskogo universiteta. Serija 2, vyp. 1 (1987), S. 89 nennt diese Gruppe kulturell-informative bzw. sozial-informative Funktion.

62. Vgl. bei CSIGE, Katalin: Személynevek frazeológiai egységekben. Budapest 1986 (= Magyar Névtani Dolgozatok 62), S. 23 - 24.

63. Vgl. den Hinweis von CSIGE, Katalin: (siehe Anm. 59), S. 145 auf BABAEVA, L. B.: Imena sobstvennye $v$ poslovicach i pogovorkach. In: Onomastika Povolž'ja 3, Ufa 1973, S. 402 - 406.

64. Vgl. STEPANOVA, L. I.: (siehe Anm. 61), S. 89.

65. Vgl. auch bei CSIGE, Katalin: (siehe Anm. 59), S. 146.

66. LICHOVIDOVA, T. V.: Frazeologičeskie edinicy s imenami sobstvennymi $v$ sovremennom anglijskom jazyke. In: Inostrannye jazyki v škole 1971/6, S. 25; GARIFULIN, L. B. - ANTONOVA, M. K.: (siehe Anm. 16), S. 163.

67. Vgl, den Hinweis von OCHŠTAT, R. I.: (siehe Anm. 49), S. 90 auf AVALIANI, Ju. Ju. - ROJZENZON, L. I.: O razgraničenii sinonimii i variantnosti frazeologičeskich edinic. In: Voprosy frazeologii i sostavlenija frazeologičeskich slovarej. Baku 1969, S. 71.

68. BÉKÉS, István: (siehe Anm. 25), S. 132.

69. Vgl. "Ugye, ettől aligha leszek krôzus, és van, amikor a munkaadó merő trehányságból nem fizet." (Népszabadság, 25. Juli 1987, S. 18.)

70. Magyar értelmezó kéziszótár. Hrsg.: von Juhász, József/Szőke, István /O. Nagy, Gábor/Kovalovszky, Miklós. 4. Aufl., Budapest 1980, S. 823.

71. VgI. OCHSTAT, R. I.: (siehe Anm. 49), S. 89 f.

72. Vgl. dazu OCHŠTAT, R. I.: (siehe Anm. 49), S. 90.

73. Vgl. "Képzeljétek, ha azt irta volna az újság, hogy szökdösős volt, akkor bizony Tolnát-Baranyát kellett volna bejárni utána." (Magyar Hírlap, 22. Sept. 1986, 5. 3) bzw. "Elmúlt egy délelốtt, bejártam ungot-berket és fél Budapestet, de a szög maradt." (Esti Hírlap, 14. Nov. 1986, S. 6.) 
74. Vgl. für das Englische bei MANUŠKINA, G. P.: (siehe Anm. 14), S. 24 f.; für das Deutsche bei FÖLDES, Csaba: (siehe Anm. 19) 1987, S. 17 f.

75. FÖLDES, Csaba: Magyar - német - orosz beszédfordulatok. A három nyelv azonos jelentésú állandósult szókapcsolatai. Budapest 1987, S. 58. 